дружелюбным, а вот Интернет-пространство воспринимается им, как достаточно агрессивная среда.

По итогам проведенного нами эмпирического исследования, мы можем сформулировать следующий вывод:

По результатам анкетирования большинство респондентов не считают себя зависимыми от Интернета, однако необходимо обратить внимание на тот факт, что 31 респондент указали на то, что они зарегистрированы более, чем в 2-х социальных сетях. Это говорит о том, что они достаточно сильно погружены в виртуальное пространство, однако также необходимо отметить тот факт, что само наличие страниц в нескольких социальных сетях не обязательно говорит о том, что респондент активно ими пользуется. Также 48 респондентов указали на то, что они имеют более 2-х игровых аккаунтов, что является косвенным признаком больших временных затрат на онлайн игры. Несмотря на это 65 респондентов предпочитают живое общение по отношению к виртуальному общению; 61 респондент отмечают, что реальный мир является наиболее ярким, насыщенным, богатым; 72 респондента ответили, что по их представлению больше эмоций также можно получить в реальном мире.

На фоне данной статистики ответов возникает резонный вопрос: если большинство респондентов воспринимают реальный мир более ярким и насыщенным, то почему такой высокий показатель ответов по количеству социальных сетей и игровых аккаунтов? Данный вопрос требует дальнейшего исследования.

1. Воробьева И. В., Кружкова О. В. Социально-психологические аспекты восприимчивости молодежи к воздействиям среды Интернет // Образование и наука. 2017. №9. URL: https://cyberleninka.ru/article/n/sotsialno-psihologicheskie-aspekty-vospriimchivosti-molodezhi-kvozdeystviyam-sredy-internet (дата обращения: 25.05.2021).

2. Левин Л. М., Отечественные исследования интернет-зависимости и погруженности в социальные сети // [Электронный ресурc]. URL: https://elibrary.ru/item.asp?id=42992187\&

3. Кузьмина Т.В., Интернет-увлеченность, интернет-зависимость, интернет-полезность: осознанный выбор студента // [Электронный ресурс]. URL: https://elibrary.ru/item.asp?id=42663780

4. Регуш Л. А., Алексеева Е. В., Веретина О. Р., Орлова А. В., Пежемская Ю. С. Особенности мышления подростков, имеющих разную степень погруженности в интернет-среду // Известия РГПУ им. А. И. Герцена. 2019. №194. URL: https://cyberleninka.ru/article/n/osobennosti-myshleniyapodrostkov-imeyuschih-raznuyu-stepen-pogruzhennosti-v-internet-sredu (дата обращения: 25.05.2021).

5. М. Кастельс. Информационная эпоха: экономика, общество и культура. М., 2000, 606с.

6. Усанова Д. О. Виртуальная культура как феномен современности и ее репрезентация в субкультурных практиках // [Электронный ресурс]. URL: https://cyberleninka.ru/article/n/virtualnayakultura-kak-fenomen-sovremennosti-i-ee-reprezentatsiya-v-subkulturnyh-praktikah

\title{
Вилкова И.А. \\ Теория и практика в решении задачи успешности подготовки специалистов профессиональными образовательными организациями
}

Ленинградский государственный университет им. А. С. Пушкина (Россия, Санкт-Петербург)

doi: 10.18411/lj-06-2021-297

\section{Аннотация}

Материалы, представленные в статье, посвящены изучению теоретических и практических аспектов в решении задачи подготовки выпускников, в рамках профессиональных образовательных организаций. В работе приводятся результаты психографических исследований, проведенных на различных базах обучения студентов среднего профессионального образования. На основе сравнительной интерпретации полученных данных, сделано заключение о возможных направлениях повышения 
уровня подготовки специалистов среднего звена, с позиций компетентностного подхода.

Ключевые слова: компетенции, профессионально важные качества, компетентностный подход, индивидуально-психологические характеристики, свойства личности, успешность обучения, учебно-профессиональная деятельность, зкспертная оценка.

\section{Abstract}

The materials presented in the article are devoted to the study of theoretical and practical aspects of solving the problem of training graduates in the framework of professional educational organizations. The article presents the results of psychographic studies conducted on various educational bases for students of secondary vocational education. On the basis of a comparative interpretation of the data obtained, a conclusion is made about possible ways to improve the level of training of middle-level specialists from the standpoint of the competence approach.

Keywords: competencies, professionally important qualities, competence approach, individual psychological characteristics, personality traits, learning success, educational and professional activities, expert assessment.

Современный, компетентностный подход в образовании, уже длительное время занимает лидирующие позиции в обсуждениях ученых и практиков. Данное обстоятельство обусловлено тем, что в настоящем, информационном обществе, постоянно происходит переосмысление специфики и объема предыдущего этапа стремительно развивающегося общества, поскольку последующий требует уже нового подхода, новых взглядов и практических решений. Таким образом, требования к подготовке и оценке качества данной подготовки сегодняшних специалистов, повышаются и меняются одновременно. Отсюда следует, что компетентностный подход, имеющий конечной целью обучение практико-ориентированных кадров, отвечающих требованиям взыскательных работодателей, не может не переосмысливаться и не развиваться. Зачастую выпускники, в том числе, системы среднего профессионального образования (далее - СПО), не имеют необходимых практических навыков. Следовательно, для профессиональных образовательных организаций актуальна задача обновления образовательных программ и самой системы подготовки специалистов, соответствующих современному уровню развития производственных, информационных технологий, общества в целом.

Президент Российской Федерации, В. В. Путин, в своих выступлениях $[5,6]$, неоднократно говорил о необходимости ускорения модернизации среднего профессионального образования, поднимая престиж рабочих профессий. Широкое распространение, по стране, приобретают такие проекты, как Национальный чемпионат WorldSkills Russia и демонстрационный экзамен (по международным стандартам WorldSkills), оценивающие уровень формирования профессиональных компетенций. Таким образом, успешность профессионального образования, сегодня, можно трактовать как гарант конкурентоспособности выпускников СПО на рынке труда.

В настоящее время, в профессиональной и образовательной сферах, существует множество определений понятия «компетенция» (Зимняя И. А., 2013; Зотов В. В., 2017; Толочек В. А., 2014, 2019; Набиев В. Ш., Дьяконова О. О., Истомина А. А., Панкратова О. Г., 2016), но общим в них является то, что индивидуальнопсихологические и личностные свойства человека выступают внутренними условиями её формирования. 
Необходимо отметить, что в структуру профессионально важных качеств (далее - ПВК), обеспечивающих эффективность профессиональной деятельности, входят: способности (общие и специальные; преимущественно врожденные и преимущественно социальные), социально-психологические свойства личности, знания и навыки. Но психофизиологические и личностные качества наиболее значимы в упомянутой структуре $[1,3]$. Следовательно, в условиях компетентностного подхода, изучение психологических детерминант успешности обучения (овладения профессиональными компетенциями) студентов профессиональных образовательных организаций, является важной и актуальной задачей, имеющей множество вариантов решения.

На основании вышеизложенного, считается возможным предположить, что наличие и степень развития индивидуально-психологических и личностных качеств, необходимых для оптимальной профессиональной самореализации, по определенной специальности, определяют успешность учебно-профессиональной деятельности студентов СПО, а, следовательно, и формирования профессиональных компетенций.

На базе Выборгского института (филиала) ГАОУ ВО ЛО «ЛГУ им. А. С. Пушкина», нами было проведено психографическое исследование. Применялся метод экспертной оценки профессионально важных качеств, с помощью опросника Т. П. Зинченко. Экспертами были преподаватели института, в количестве 16 человек (имеющие рабочий стаж не менее 5 лет), которые, в индивидуальном порядке, давали ответы на 161 вопрос данного опросника. Полученные результаты проходили математико-статистическую обработку с использованием программы Excel из пакета Ms Office (по алгоритму А. Г. Маклакова) [3]. Определялось среднее значение полученных показателей экспертов (x), в отношении важности каждого профессионального качества (далее - ПК), обусловливающего успешность будущей работы по профессии (для различных направлений СПО). Для рассмотрения принимались средние значения оценок экспертов от 2,5 и выше, и от -2,5 и ниже. Высокие средние значения свидетельствовали о значимости того или иного ПК для успешности профессиональной деятельности, по определенной специальности СПО и наоборот, низкие средние значения определяли недопустимые ПК для успешного выполнения профессионального долга. На следующем этапе вычислялся разброс вариантов ответов, означающий степень несогласованности мнений экспертов, таким образом, определялось стандартное отклонение (s). Следовательно, надо было выбрать максимальные средние значения, при минимальных показателях стандартного отклонения [1].

Для решения вопроса, предлагаемого к рассмотрению в рамках данного исследования, были выбраны два направления СПО: «Дошкольное образование» и «Преподавание в начальных классах». Помимо определения важных ПК, с точки зрения экспертов-преподавателей (алгоритм которого приводился выше), было проведено дополнительное исследование на базах прохождения студентами, указанных специальностей, производственной практики, а именно: в Муниципальном бюджетном дошкольном образовательном учреждении (далее - МБДОУ) №35 и Муниципальном бюджетном образовательном учреждении: средняя образовательная школа (далее МБОУ СОШ) №10 г. Выборг. Эксперты-воспитатели МБДОУ №35 и эксперты-учителя МБОУ СОШ №10 (в количестве 12 и 16 человек, соответственно, имеющие стаж работы не менее 5 лет, в обоих случаях) так же, как и эксперты-преподаватели Выборгского института (филиала), давали ответы на вопросы о значимых ПК, по опроснику Т. П. Зинченко. Полученные данные обрабатывались по алгоритму, описанному ранее.

Результаты проведенных исследований сведены в таблицы 1 и 2. 
Таблиияа 1

Профессионально важные качества для специиальности «Дошкольное образование»

\begin{tabular}{|c|c|c|c|c|c|}
\hline \multirow[t]{2}{*}{$\begin{array}{l}\text { № } \\
\text { ח/ח }\end{array}$} & \multirow[t]{2}{*}{ Профессионально важные качества } & \multicolumn{2}{|c|}{$\begin{array}{c}\text { эксперты- } \\
\text { воспитатели } \\
\text { (МБДОУ №35) }\end{array}$} & \multicolumn{2}{|c|}{$\begin{array}{c}\text { эксперты- } \\
\text { преподаватели } \\
\text { (Выборгский } \\
\text { институт (филиал) }\end{array}$} \\
\hline & & $\mathrm{X}$ & $\mathrm{S}$ & $\mathrm{X}$ & $\mathrm{S}$ \\
\hline 1 & $\begin{array}{l}\text { Эмоциональная устойчивость при принятии } \\
\text { ответственного решения }\end{array}$ & 3,00 & 0,00 & 2,75 & 0,46 \\
\hline 2 & $\begin{array}{l}\text { Способность охватить суть основных } \\
\text { взаимосвязей, присущих проблеме }\end{array}$ & 2,80 & 0,45 & & \\
\hline 3 & $\begin{array}{l}\text { Способность к длительному взаимодействию с } \\
\text { другими членами группы }\end{array}$ & 3,00 & 0,00 & 2,63 & 0,52 \\
\hline 4 & Способность к обучению, переучиванию & 2,80 & 0,45 & & \\
\hline 5 & $\begin{array}{l}\text { Способность принять правильное решение при } \\
\text { недостатке необходимой информации или при } \\
\text { отсутствии времени на ее осмысление }\end{array}$ & 3,00 & 0,00 & & \\
\hline 6 & $\begin{array}{l}\text { Способность действовать в экстремальных } \\
\text { (чрезвычайных) ситуациях }\end{array}$ & 3,00 & 0,00 & & \\
\hline 7 & $\begin{array}{l}\text { Способность быстро принимать решение при } \\
\text { изменении ситуации }\end{array}$ & 3,00 & 0,00 & & \\
\hline 8 & $\begin{array}{l}\text { Быстрая реакция на неожиданный слуховой } \\
\text { сигнал посредством определенных движений }\end{array}$ & 2,80 & 0,45 & & \\
\hline 9 & $\begin{array}{l}\text { Способность к легкому общению с другими } \\
\text { членами коллектива }\end{array}$ & 3,00 & 0,00 & & \\
\hline 10 & $\begin{array}{l}\text { Способность в течение короткого времени } \\
\text { удерживать в памяти необходимый материал } \\
\text { (знаки, цифры) }\end{array}$ & 2,80 & 0,45 & & \\
\hline 11 & $\begin{array}{l}\text { Способность длительное время сохранять } \\
\text { устойчивое внимание, несмотря на усталость и } \\
\text { посторонние раздражители }\end{array}$ & 3,00 & 0,00 & & \\
\hline 12 & Умение узнавать и различать цвета & 3,00 & 0,00 & & \\
\hline 13 & Способность найти подход к подчиненным & 2,80 & 0,45 & & \\
\hline 14 & $\begin{array}{l}\text { Способность быстро менять направление } \\
\text { внимания }\end{array}$ & 3,00 & 0,00 & & \\
\hline 15 & $\begin{array}{l}\text { Способность не ослаблять внимания под } \\
\text { влиянием испуга или неожиданных впечатлений }\end{array}$ & 3,00 & 0,00 & & \\
\hline 16 & $\begin{array}{l}\text { Способность понимать людей, причины их } \\
\text { поступков, роль каждого человека в группе и } \\
\text { взаимоотношения между ними }\end{array}$ & 3,00 & 0,00 & & \\
\hline 17 & Настойчивость в достижении цели & 3,00 & 0,00 & & \\
\hline 18 & $\begin{array}{l}\text { Способность точно и уверенно узнавать предметы } \\
\text { по их форме и величине }\end{array}$ & 2,80 & 0,45 & & \\
\hline 19 & $\begin{array}{l}\text { Способность объективно оценивать свои } \\
\text { достижения, силы и возможности }\end{array}$ & 2,80 & 0,45 & & \\
\hline 20 & $\begin{array}{l}\text { Быстрая реакция на внезапные зрительные } \\
\text { раздражители (сигналы) посредством } \\
\text { определенных движений }\end{array}$ & 3,00 & 0,00 & & \\
\hline 21 & $\begin{array}{l}\text { Способность выполнять сильные и грубые } \\
\text { движения }\end{array}$ & $-2,60$ & 0,55 & & \\
\hline 22 & $\begin{array}{l}\text { Способность разрешать конфликты, т.е. находить } \\
\text { выход из конфликтной ситуации }\end{array}$ & 3,00 & 0,00 & & \\
\hline 23 & Умение поставить себя на место другого человека & 3,00 & 0,00 & & \\
\hline 24 & Умение коротко и ясно спрашивать & 3,00 & 0,00 & & \\
\hline 25 & $\begin{array}{l}\text { Умение планировать совместную работу с учетом } \\
\text { интересов и возможностей каждого члена } \\
\text { коллектива }\end{array}$ & 3,00 & 0,00 & & \\
\hline 26 & $\begin{array}{l}\text { Способность к эмоциональной отзывчивости на } \\
\text { переживания других людей }\end{array}$ & 3,00 & 0,00 & & \\
\hline
\end{tabular}




\begin{tabular}{|c|c|c|c|c|c|}
\hline 27 & Уравновешенность, самообладание & 3,00 & 0,00 & & \\
\hline 28 & $\begin{array}{l}\text { Умение формировать и поддерживать } \\
\text { благоприятный социально-психологический } \\
\text { климат в коллективе }\end{array}$ & 3,00 & 0,00 & & \\
\hline 29 & $\begin{array}{l}\text { Способность быстро переключать внимание с } \\
\text { одного вида деятельности на другой }\end{array}$ & 2,80 & 0,45 & & \\
\hline 30 & $\begin{array}{l}\text { Способность к быстродействию в условиях } \\
\text { дефицита времени }\end{array}$ & 2,80 & 0,45 & & \\
\hline 31 & $\begin{array}{l}\text { Способность к величайшему напряжению } \\
\text { внимания в определенные моменты }\end{array}$ & 2,80 & 0,45 & & \\
\hline 32 & $\begin{array}{l}\text { Способность ощущать душевное состояние } \\
\text { другого человека }\end{array}$ & 2,80 & 0,45 & & \\
\hline 33 & Соблюдение моральных норм поведения & 3,00 & 0,00 & 2,63 & 0,74 \\
\hline 34 & $\begin{array}{l}\text { Отношение к требованиям социального } \\
\text { окружения как обязательным }\end{array}$ & 2,80 & 0,45 & & \\
\hline 35 & Соблюдение общепринятых норм поведения & 3,00 & 0,00 & 2,55 & 0,71 \\
\hline 36 & Стремление к обострению конфликта & $-3,00$ & 0,00 & & \\
\hline 37 & $\begin{array}{l}\text { Склонность к ожесточенным дискуссиям и } \\
\text { провоцированию конфликтов }\end{array}$ & $-3,00$ & 0,00 & & \\
\hline 38 & $\begin{array}{l}\text { Неуравновешенность и чрезмерная жестокость по } \\
\text { отношению к другим людям }\end{array}$ & $-3,00$ & 0,00 & $-2,75$ & 0,71 \\
\hline
\end{tabular}

Примечание: $X$-среднее значение, $S$-стандартное отклонение

Таблица 2

Профессионально важные качества для спещиальности «Преподавание в начальных классах»

\begin{tabular}{|c|c|c|c|c|c|}
\hline \multirow[t]{2}{*}{$\begin{array}{l}\text { № } \\
\Pi / \Pi\end{array}$} & \multirow[t]{2}{*}{ Профессионально важные качества } & \multicolumn{2}{|c|}{$\begin{array}{c}\text { эксперты-учителя } \\
\text { (МБОУ «СОШ } \\
\text { №10») }\end{array}$} & \multicolumn{2}{|c|}{$\begin{array}{c}\text { эксперты- } \\
\text { преподаватели } \\
\text { (Выборгский } \\
\text { институт (филиал) }\end{array}$} \\
\hline & & $\mathrm{X}$ & $\mathrm{S}$ & $\mathrm{X}$ & $\mathrm{S}$ \\
\hline 1 & $\begin{array}{l}\text { Эмоциональная устойчивость при принятии } \\
\text { ответственного решения }\end{array}$ & 2,60 & 0,55 & 2,78 & 0,44 \\
\hline 2 & Способность найти подход к подчиненным & 2,80 & 0,45 & & \\
\hline 3 & $\begin{array}{l}\text { Способность понимать людей, причины их } \\
\text { поступков, роль каждого человека в группе и } \\
\text { взаимоотношения между ними }\end{array}$ & 2,60 & 0,55 & & \\
\hline 4 & $\begin{array}{l}\text { Способность разрешать конфликты, т.е. } \\
\text { находить выход из конфликтной ситуации }\end{array}$ & 2,60 & 0,55 & & \\
\hline 5 & $\begin{array}{l}\text { Умение поставить себя на место другого } \\
\text { человека }\end{array}$ & 2,60 & 0,55 & & \\
\hline 6 & $\begin{array}{l}\text { Умение планировать совместную работу с } \\
\text { учетом интересов и возможностей каждого } \\
\text { члена коллектива }\end{array}$ & 2,80 & 0,45 & & \\
\hline 7 & $\begin{array}{l}\text { Умение формировать и поддерживать } \\
\text { благоприятный социально-психологический } \\
\text { климат в коллективе }\end{array}$ & 2,60 & 0,55 & & \\
\hline 8 & Соблюдение моральных норм поведения & 2,80 & 0,45 & & \\
\hline 9 & $\begin{array}{l}\text { Отношение к требованиям социального } \\
\text { окружения как обязательным }\end{array}$ & 2,60 & 0,55 & & \\
\hline 10 & Соблюдение общепринятых норм поведения & 2,60 & 0,55 & & \\
\hline 11 & $\begin{array}{l}\text { Способность самостоятельно принимать } \\
\text { решения }\end{array}$ & 2,60 & 0,55 & & \\
\hline 12 & $\begin{array}{l}\text { Способность отстаивать собственную точку } \\
\text { зрения }\end{array}$ & 2,60 & 0,55 & & \\
\hline 13 & $\begin{array}{l}\text { Стремление находить компромиссное решение с } \\
\text { партнером, в группе }\end{array}$ & 2,60 & 0,55 & & \\
\hline 14 & $\begin{array}{l}\text { Способность к длительному взаимодействию с } \\
\text { другими членами группы }\end{array}$ & & & 2,78 & 0,44 \\
\hline
\end{tabular}

Примечание: $X$-среднее значение, $S$-стандартное отклонение 
Сравнительные данные, приведенные в таблице 1, позволяют говорить о том, что эксперты-практики (воспитатели МБДОУ №35), в отличие от экспертовпреподавателей Выборгского института, отмечали те ПК, необходимость которых подтверждена их профессиональным опытом и требованиями должностной инструкции. Например, можно говорить о том, что ответственность за детей, которую несут воспитатели, позволила им выделить такие ПВК, как: «способность принимать правильные решения при недостатке необходимой информации или при отсутствии времени на ее осмысление»; «способность действовать в экстремальных (чрезвычайных) ситуациях», «способность быстро принимать решение при изменении ситуации»; «способность длительное время сохранять устойчивое внимание, несмотря на усталость и посторонние раздражители»; «способность быстро менять направление внимания»; «способность не ослаблять внимание под влиянием испуга или неожиданных впечатлений».

Можно предположить, что практика делового общения, профессионального роста, а также необходимость интеллектуального развития, послужили основой для определения ими таких ключевых ПК, как: «эмоциональная устойчивость при принятии ответственного решения»; «способность к длительному взаимодействию с другими членами группы»; «способность к обучению, переучиванию»; «умение коротко и ясно спрашивать»; «умение поставить себя на место другого человека».

К аналогичному выводу можно прийти, интерпретируя сравнительные данные из таблицы 2. Учителя СОШ №10, в отличие от преподавателей Выборгского института, дополнили список такими ПК, которые можно отнести к личностным характеристикам профессионала. Например: «способность разрешать конфликты, т.е. находить выход из конфликтной ситуации»; «умение поставить себя на место другого человека»; «соблюдение общепринятых норм поведения»; «способность к длительному взаимодействию с другими членами группы». О необходимости учителя иметь высокий уровень интеллекта, говорят такие, выбранные ими, ПК, как: «способность самостоятельно принимать решения», «способность отстаивать собственную точку зрения».

Обобщая полученные результаты, можно сделать вывод о том, что практическая деятельность специалистов дает более полное и глубокое представление о профессии, о чем свидетельствует значительное расширение ими диапазона ПВК, по сравнению с преподавателями института, акцентирующих свое внимание на теоретической подготовке студентов.

Можно говорить о том, что полученные сведения подтверждают точку зрения ряда ученых (которую мы разделяем) о том, что индивидуально-психологические, личностные, профессиональные качества специалиста проявляются в конкретной организации, в рамках определенной профессиональной деятельности (О. А. Белова, В. В. Зотов, В. Г. Коновалова, Е. А. Митрофанова). «Компетенции суть столь же деятельностные, сколь и организационные сущности. И поэтому о тех или иных компетенциях можно осмысленно говорить лишь в определенных организационнодеятельностных контекстах» [4, с.9].

Следовательно, под уровнем формирования компетенций у выпускников, в частности, системы СПО, следует понимать степень их готовности к выполнению профессиональной работы, в соответствии с требованиями ее качества [2]. Кроме того, обнаруженные различия в количестве значимых ПК, для каждой специальности, с позиций практического и теоретического подходов подготовки студентов СПО, могут служить обоснованием необходимости корректировки образовательных программ среднего профессионального образования, заключающейся в разработке новых и 
совершенствовании прежних структур компетенций, по направлениям подготовки специалистов, в рамках ФГОС СПО нового поколения.

$$
* * *
$$

1. Вилкова, И. А. Профессионально важные качества, определяющие успешность владения профессией в структуре среднего профессионального образования [Текст] / И. А. Вилкова // Вестник ЛГУ им. А. С. Пушкина. - 2018. - № 2. - С. $72-81$.

2. Зотов, В. В. Компетенции и профессионально важные качества: соотношение понятий и поле применимости в образовании, профессиональной сфере и государственной службе [Текст] / В. В. Зотов // Вестник Тамбовского ун-та. Серия: Общественные науки. - 2017. - № 2 (10). - Т. 3. - С. 28 -33 .

3. Маклаков, А. Г. Профессиональный психологический отбор персонала. Теория и практика [Текст] / А. Г. Маклаков. - СПб.: Питер, 2008. - 480 с.

4. Митрофанова, Е. А., Коновалова, В. Г., Белова, О. Л. Управление персоналом: теория и практика. Компетентностный подход в управлении персоналом [Текст] / Е. А. Митрофанова, В. Г. Коновалова, О. Л. Белова. - М.: Проспект, 2013. - 65 с.

5. Педсовет. Путин: технологический прорыв страны зависит от развития СПО [Электронный pecypc] / Режим доступа: https: // yandex. ru / turbo / pedsovet. org.

6. Стенографический отчет о совещании по развитию системы среднего профессионального образования [Электронный ресурс] / Режим доступа: http: // kremlin. ru. / events / president / news / 56992.

\section{Заборина Л.Г., Овчинникова Ж.В. \\ Эмпирическое исследование самооценки и уровня притязаний взрослых людей, имеющих группу инвалидности}

Забайкальский государственньй университет

(Россия, Чита)

doi: $10.18411 / \mathrm{j}-06-2021-298$

\section{Аннотация}

В статье представлены результаты диагностического исследования самооценки и уровня притязаний у взрослых людей $(\mathrm{N}=50)$, имеющих первую, вторую или третью группу инвалидности. Выделены особенности самооценки (CO) и уровня притязаний (УП) у мужчин и женщин с инвалидностью, а так же особенности СО и УП у лиц с разной группой инвалидности.

Ключевые слова: инвалидность, самооценка, уровень притязаний, группы инвалидности.

\section{Abstract}

The article presents the results of a diagnostic study of self-esteem and the level of claims in adults with the first, second or third disability group. The features of self-esteem and the level of claims in men and women with disabilities, as well as the features of self-esteem and the level of claims in people with different groups of disabilities are highlighted.

Keywords: disability, self-esteem, level of claims, disability groups.

Согласно Федеральной государственной информационной системе «Федеральный реестр инвалидов», в России насчитывается более 11 миллионов человек, имеющих различную группу инвалидности. Из них более 6 миллионов - это женщины, более 4 миллионов - мужчины, и более 600 тысяч - это дети-инвалиды.

Инвалидность - это специфическая особенность развития и состояния личности, часто сопровождающаяся ограничениями жизнедеятельности в самых разнообразных её сферах. Вследствие этого, люди, имеющие инвалидность, воспринимаются обществом как отдельная категория граждан, особая демографическая группа. 